\title{
Long-Term Effects of a Comprehensive Police Suicide Prevention Program
}

\author{
22-Year Follow-Up
}

\author{
Brian L. Mishara ${ }^{1,2}$ and Louis-Francis Fortin ${ }^{3}$ \\ ${ }^{1}$ Centre for Research and Intervention on Suicide, Ethical Issues and End-of-Life Practices, Université du Québec à Montréal, QC, Canada \\ 2Department of Psychology, Université du Québec à Montréal, QC, Canada \\ ${ }^{3}$ Police Service of the City of Montreal (SPVM), Montreal, QC, Canada
}

\begin{abstract}
Background: Mishara and Martin (2012) reported decreases in suicides 12 years after implementation of a police suicide prevention program. Aims: We aimed to determine whether suicide decreases were sustained 10 years later. Method: We examined coroners' investigations of police deaths from 2009 through 2018. Results: From 2009 to 2018, Montreal suicide rates increased but this was not significantly different from the previous 12 years and the rate for other Quebec police remained significantly higher than Montreal ( $p<.006)$. The 22-year Montreal postprogram rate was significantly lower than the preprogram rate $(p<.002)$, and the 22-year rate for other police during the same years was not significantly different from earlier. Limitations: Uncontrolled factors may have influenced the rates, including the $11 \%$ increase in women in the Montreal police. The observed mean aging of the Montreal police personnel would have been expected to bias toward finding increases in suicides. However, the maintenance of decreases in suicide rates was observed. Conclusion: The decrease in suicides observed 12 years after the program was sustained for another 10 years, and appears related to the program. Rates for comparable police remained higher. A continuing comprehensive suicide prevention program tailored to the context may reduce suicides for extended time periods.
\end{abstract}

Keywords: suicide, prevention, program, police, workplace

Mishara and Martin (2012) published the results of an evaluation of the effects of a multifaceted program to prevent suicides in the police force in Montreal, Quebec, Canada. They compared changes in suicide rates in the Montreal police 11 years before the program began with the suicide rates 12 years after the program was initiated. The program consisted of providing half-day training for all police officers and a 1-day training for supervisors and union representatives, as well as establishment of a volunteer police telephone helpline and a publicity campaign. These activities were supported by psychologists available $24 \mathrm{~h}$ a day for confidential support. They found that in the 12 years after the program began, the suicide rate decreased significantly by $79 \%$ (from 30.5 / 100,000 per year to $6.4 / 100,000$ per year). The other police forces in the Province of Quebec, which did not have a workplace suicide prevention program, had a nonsignificant $(11 \%)$ increase when comparing those two periods (from 26.0/100,000 per year to 29.0/100,000 per year). The authors concluded that the decrease in suicides appears to be related to this program, since suicide rates for comparable populations did not decrease and there was no major change in the function, training, or recruitment to explain the differences. This paper describes changes in the program and in suicide rates for another 10 years, that is, in the 22 years since the Montreal police suicide prevention program was initiated, comparing suicide rates in Montreal with the rates in other police forces in the Province of Quebec during the same periods.

\section{Suicide Among Police Officers}

Although active employment is a protective factor against suicide, and police officers are generally screened for mental health problems, which are associated with increased suicide risk, police often have a greater risk of suicide than comparable populations (Fields \& Jones, 1999; Hackett \& Violanti, 2003). However, this is not 
always the case. Marzuk et al. (2002) found that New York City police officers had suicide rates equal to or slightly lower than the city's resident population. In the Province of Quebec (Charbonneau, 2000), the suicide rate for male police officers was equivalent to the standardized rate for males in the general population. A metaanalysis of 101 reports of police suicide rates (Loo, 2003) found important variations between police forces, regions, and countries, with the mean rate for all the studies being lower than the comparable mean of the general population. Milner et al. $(2013,2017)$ reported that suicide rates in protective and emergency service employees, which include police, defense forces, and ambulance and fire services, are significantly higher than corresponding rates in members of the general working population.

The higher rates have generally been explained by having greater job stress in protective and emergency service employees (Finney et al., 2013; Webster, 2013), as well as having ready access to means for suicide, access to firearms in police, and access to lethal medications in emergency health workers (Skegg et al., 2010).

Witt et al. (2017) published a systematic review and meta-analysis of the effectiveness of suicide prevention programs for emergency and protective services employees. They identified 13 studies, of which six reported sufficient data on suicide rates to conduct quantitative analyses. They found that these programs were associated with a decrease of approximately $50 \%$ in suicide rates over an average follow-up period of 5.25 years. They emphasized the need for further research in this area. Because of the low incidence of deaths by suicide and the relatively small populations of police officers in any municipality, it is important to study effects on suicide death rates over an extended period, and to compare rates with, to the extent possible, comparable populations as a control group. This article describes how the Montreal police suicide prevention program was modified following the previous evaluation (Mishara \& Martin, 2012), and how its implementation has continued to date. We report on changes in suicide rates in the Montreal police force, compared with police officers elsewhere in Quebec, during the 10 years following the initial 12-year impact study reported previously, for a total follow-up period of 22 years.

\section{Program Goals, Activities, and Modifications}

The original program, called "Together for Life," that we described previously (Mishara \& Martin, 2012) had four components. First, all police officers received a half-day of training conducted by psychologists familiar with the police work environment. The training focused on myths and realities of suicide, explaining about resources available and emphasizing the collective responsibility of all police personnel to help others in distress. The second activity was a full day of training for supervisors (sergeants) and union representatives, which expanded on the half-day training by emphasizing how to identify someone at risk and how to ask about suicidal intention, as well as discussing the police department policy of removing an officer's service revolver if she or he was determined to be at risk of suicide. Third, a telephone helpline staffed by volunteer police officers was available to all police personnel. Fourth, there was a publicity campaign to familiarize police personnel with the available services and to inform them about suicide and suicide prevention activities, developed by the psychology service of the police department.

After the 12-year follow-up and the evaluation of the program (Mishara \& Martin, 2012), activities were expanded and their content changed to respond to recommendations from the program's evaluation. All police officers currently employed by the Montreal police department continued to receive a half-day of training in each of the 54 police units where they worked. This time the training was conducted by both a police psychologist and a fellow police officer to provide both expert information and the personal experiences of a fellow officer. Having another police officer share personal experiences was included to create a more open environment to talk about personal troubles, and to provide a model of resilience, including a real-life demonstration of how to express problems to others. This activity was highly appreciated, as indicated by quite positive comments on evaluation sheets. The three other major components - training of supervisory personnel and union representatives, police helpline, and publicity campaign - continued and were regenerated with new visual presentations and updated content. The new program added a new component: training of peergatekeepers, police officers who received a gatekeeper training program that was inspired by the Quebec Provincial gatekeeper training program, but adapted to the realities of the police milieu. The role of this program was to help police officers identify coworkers who are at risk and refer them to potential sources of help.

In the paper by Mishara and Martin (2012), detailed evaluations of the implementation of each of the program's components were presented. They reported high levels of appreciation and evidence of uptake of program content in the behaviors of trained supervisors. The appreciation of the program was explained on evaluation forms as being due to the content being presented in a manner that was congruent with their experiences ("they 
talked our language"), and the high level of confidence in the police psychological support services. This is an ongoing program with continued publicity each year and training being conducted on a rotating basis in all of the 54 police stations and headquarters. However, because of changes in assignments, some personnel may not have an opportunity to participate in the training when they change work locations before training occurs in their unit, and move to a unit where the training already occurred that year.

\section{Method}

\section{Participants}

Table 1 shows characteristics of the members of the police force as of December 31, 2000, as reported in the 12 years follow-up study (Mishara \& Martin, 2012), as well as the characteristics as of December 31, 2019. The proportion of women in the force increased from $22.1 \%$ in 2000 to $33.0 \%$ in 2018. The age distribution indicates an aging of the police force members, with the highest proportion in 2000 being age 30-39 and in 2018 age 40-49. We obtained the numbers of police working in Montreal and the other police in the province from the annual reports of the police forces for 1997-2008, and we verified the absence of specific suicide prevention programs in the other Quebec police by contacting the other police departments to ask about this. However, all Quebec police departments indicated that all police personnel have access to trained counsellors as part of their Employee Assistance Programs. Furthermore, we are aware that mental health and suicide are subjects that have been receiving increased attention as part of the curriculum of the Quebec National Police Academy ("École nationale de police du Québec") and other higher education training programs for police personnel in Quebec.

\section{Procedure}

The Quebec Coroner's Office conducts an investigation of all deaths that are not from natural causes to identify the cause of deaths, and to make recommendations for prevention. Local coroners conduct the initial investigation based upon police reports, medical information, and interviews with family, witnesses, and other persons they feel would be helpful. When they find that there is missing information, they are in doubt about the cause of death, or implications for prevention need more
Table 1. Description of Montreal police personnel on December 31, 2000 and December 31, 2018

\begin{tabular}{|c|c|c|}
\hline & $2000, N(\%)$ & 2018, N (\%) \\
\hline \multicolumn{3}{|l|}{ Sex } \\
\hline Men & 3,255 (77.9\%) & 3,052 (66.97\%) \\
\hline Women & $923(22.1 \%)$ & 1,505 (33.03\%) \\
\hline Total & 4,178 (100\%) & 4,557 (100\%) \\
\hline \multicolumn{3}{|l|}{ Ranks } \\
\hline Officers & 2,998 (72\%) & $3,373(74 \%)$ \\
\hline Sergeants & $444(11 \%)$ & $388(9 \%)$ \\
\hline Sergeant detectives & 507 (12\%) & $585(13 \%)$ \\
\hline Lieutenants & $47(1 \%)$ & $30(1 \%)$ \\
\hline Lieutenant detectives & $52(1 \%)$ & $64(1 \%)$ \\
\hline Captains & 1 & - \\
\hline Captain detectives & 2 & - \\
\hline Commanders & $98(2 \%)$ & $76(2 \%)$ \\
\hline Inspectors & $9(0.2 \%)$ & $19(0.4 \%)$ \\
\hline Chief inspectors & $12(0.3 \%)$ & $17(0.4 \%)$ \\
\hline Assistant directors & $5(0.1 \%)$ & $4(0.1 \%)$ \\
\hline Associate directors & 2 & - \\
\hline Directors & 0 & 1 \\
\hline \multicolumn{3}{|l|}{ Age distribution } \\
\hline $20-29$ & $1,147(27 \%)$ & 875 (19\%) \\
\hline $30-39$ & $1,810(43 \%)$ & $1,308(29 \%)$ \\
\hline $40-49$ & $889(21 \%)$ & $1,738(38 \%)$ \\
\hline $50-59$ & $330(8 \%)$ & $628(14 \%)$ \\
\hline$\geq 60$ & 2 & $8(0.2 \%)$ \\
\hline \multicolumn{3}{|c|}{ Distribution by years of service } \\
\hline $0-4$ & 1,305 (32\%) & 935 (21\%) \\
\hline $5-9$ & $545(13 \%)$ & $374(8 \%)$ \\
\hline $10-14$ & $868(21 \%)$ & $830(18 \%)$ \\
\hline $15-19$ & $549(13 \%)$ & $958(21 \%)$ \\
\hline $20-24$ & $323(8 \%)$ & $838(18 \%)$ \\
\hline $25-29$ & $440(11 \%)$ & $524(11 \%)$ \\
\hline $30-34$ & $141(3 \%)$ & $96(2 \%)$ \\
\hline$\geq 35$ & $7(0.2 \%)$ & 2 \\
\hline
\end{tabular}

clarification, they may conduct an inquest in which they may requisition testimony and evidence from experts and others who may help them in their investigation. Police suicides are systematically identified and documented in coroners' reports. The reports from the local coroner are verified by the Office of the Chief Coroner, and when required, additional information or investigations may be conducted before the reports are finalized. We obtained from the Chief Coroner's Office their final investigation reports of all police suicides from 2009 to 2018. These reports include the name of the Quebec police force 
where the individuals had worked. Persons on leave were considered to still be employees of their police department, but retired police officers were not included, being considered to not be working as police at the time of their death. We also obtained data from the Montreal Police Department on all suicide deaths during this period, and compared our list with the information received from the coroner. There was one suicide of a Montreal police officer identified by the police department who was erroneously attributed to working elsewhere by the Coroner's Office, probably because he lived in a distant suburb from Montreal.

We calculated normalized rates for the new 10-year follow-up period and 22-year period after the program was initiated, using the same methods as in our previous study (Mishara \& Martin, 2012). We compared these rates with the rates for 1997-2008 and we compared combined 22 postprogram rates for the 22 years after the program with suicide rates before the program, from 1986 to 1996 . The significance of differences between rates was calculated with the Medcalc program, using the test-based method described by Sahai and Khurshid (1996, p. 169). Although the Montreal police annual reports indicate the age and sex distribution of their personnel for each year since 2000, this information is not available for all years and for most of the other police departments in the Province of Quebec. For this reason, we calculated crude rates rather than age- and sexstandardized rates, as in the Mishara and Martin (2012) study. While crude rates can indicate the death burden and specific needs for services for a given population, compared with another population, regardless of size, they can provide a biased indication if suicide rates are influenced by differences between Montreal and the rest of Quebec police in associated factors, such as the age and sex distributions of the police force. We know that there was an $11 \%$ increase in the proportion of women in the Montreal police force from 2000 to 2018 (Table 1), and there was a substantial increase of the mean age of Montréal police during this period. Discussions with police from other regions indicate that there appear to have been similar changes elsewhere in Quebec Province. If women in the police have a lower suicide risk as they do in the general population, the increased proportion of women could result in some decrease in suicide risk in police. However, the aging of the police force should result in substantially higher suicide rates in Montreal police, if risk by age follows the same trends as the rest of the Quebec population. In Quebec, the highest suicide rates for men and women are in the age group of 45-60, where the proportion of Montreal police doubled over this period.

\section{Results}

Table 2 shows the suicide rates for Montreal police and all other police in the Province of Quebec, during three periods: the 11 years before the program was started, the 12 years after the program began, the subsequent 10 years, as well as the combined 22 years since the program was started. The significance of differences between these rates and 95\% CIs are indicated. Previously, Mishara and Martin (2012) reported a 78\% decrease in Montreal suicide rates in the 12 years after the police suicide prevention program began, from $30.5 / 100,000$ population per year during $1986-1996$, to $6.4 / 100,000$ population per year in the 12 years after the program, from 1997 to 2008. The Montreal police rate in the subsequent 10 years, from 2009 to 2018 , was $11.1 / 100,000$, which was not significantly different from the rate in the previous 12 years after the program began. From 1986 to 1996, there were 14 deaths by suicide in the Montreal police force, from 1997 to 1998 there were four, and from 2009 to 2018 there were five.

Montreal police rates were compared with rates for the other police in the Province of Quebec. From 1986 to 1996, the suicide rate for other Quebec police Quebec was 26.0/ $100,000(n=29)$; and from 1997 to 2008, the rate was $29.0 / 100,000(n=32)$. During the 10 years from 2009 to 2018, the Montreal police suicide rate increased to 11.1/ 100,000 , but this rate was not significantly different from the previous 12 years after the program began (6.4/ $100,000)$. The rate for other police in Quebec decreased significantly $(p<.038)$ from the 12 years after the program during 1997-2008 $(29.0 / 100,000)$ to the following 10 years, 2009-2018 (15.53/100,000). However, this latter rate for 2009-2018 was significantly higher than the rate for the police in Montreal during those years $(p<$ .006). When one calculates the rate for Montreal police during the 22 years following the start of the Montreal police suicide prevention program, the postprogram rate is $8.80 / 100,000$, which is significantly lower than the preprogram rate $(p<.002)$. The 22 -year rate for other police in Quebec Province during the same years, 23.2/ 100,000 , was not significantly different from the 1986-1996 rate.

\section{Discussion}

The significant decrease in suicides observed in the first 12 years after initiating the Montreal police prevention program was sustained in the following 10 years, indicating significantly reduced suicide rates in Montreal over 22 years, when compared with the preceding 11 years 
Table 2. Police suicide rates in Montreal and the rest of Quebec before and after implementation of the police suicide prevention program, including 22-year follow-up

\begin{tabular}{|c|c|c|c|c|}
\hline Time frame & & Montreal police & Police rest of Quebec & $\begin{array}{l}\text { Comparison Montreal to } \\
\text { rest of Quebec }\end{array}$ \\
\hline Before program 1986-1996 & $\begin{array}{l}\text { Suicides } \\
\text { Population (mean) } \\
\text { Rate per 100,000 } \\
95 \% \mathrm{Cl}\end{array}$ & $\begin{array}{l}14 \\
4,178 \\
30.5 \\
18.04-51.44\end{array}$ & $\begin{array}{l}29 \\
10,131 \\
26.0 \\
18.06-37.45\end{array}$ & ns \\
\hline After program 1997-2008 & $\begin{array}{l}\text { Suicides } \\
\text { Population (mean) } \\
\text { Rate per 100,000 } \\
95 \% \mathrm{Cl}\end{array}$ & $\begin{array}{l}4 \\
5,189 \\
6.4 \\
2.31-17.88\end{array}$ & $\begin{array}{l}32 \\
9,197 \\
29.0 \\
20.19-41.64\end{array}$ & $p=.007$ \\
\hline Comparison before 1986-1996 - after 1997-2008 & & $p=.008$ & ns & \\
\hline After program 2009-2018 & $\begin{array}{l}\text { Suicides } \\
\text { Population (mean) } \\
\text { Rate per 100,000 } \\
95 \% \mathrm{Cl}\end{array}$ & $\begin{array}{l}5 \\
4,523 \\
11.1 \\
3.59-25.80\end{array}$ & $\begin{array}{l}16 \\
10,305 \\
15.50 \\
6.87-40.93\end{array}$ & $p=.006$ \\
\hline $\begin{array}{l}\text { Comparison between periods after } 1997-2008 \text { and after } \\
\text { 2009-2018 }\end{array}$ & & ns & $p=.038$ & \\
\hline 22 years combined after program 1997-2018 & $\begin{array}{l}\text { Suicides } \\
\text { Population (mean) } \\
\text { Rate per 100,000 } \\
95 \% \mathrm{Cl}\end{array}$ & $\begin{array}{l}9 \\
4,650 \\
8.8 \\
4.02-16.70\end{array}$ & $\begin{array}{l}48 \\
9,283 \\
23.2 \\
17.08-30.71\end{array}$ & $p=.006$ \\
\hline $\begin{array}{l}\text { Comparison before program 1986-1996 to } 22 \text { years } \\
\text { combined after } 1997-2018\end{array}$ & & $p=.002$ & ns & \\
\hline
\end{tabular}

Note. $\mathrm{Cl}=$ confidence interval; $\mathrm{ns}=$ non-significant. Significant differences are bolded.

before the program began. These significant reductions of $79 \%$ in the first 12 years, and $71 \%$ for the combined 22 years after the program began, appear to be related to this program. The Montreal rates remained significantly lower than the rates for police elsewhere in Quebec who did not participate in a similar program. The proportion of women, who are generally less at risk of suicide than men in Quebec, increased in Montreal by $10 \%$ during this period. However, the lack of statistical difference between the rates for the first 12 years after initiating the program and the subsequent 10 years indicates that this is not sufficient to explain the maintained lower rate, which is substantially lower than the $10 \%$ change in the proportion of women.

The aging of the police force population meant that the numbers of police personnel in the age group with the highest suicide risk in Quebec, age 45-60, increased substantially during this period. If this demographic change were to have had an influence, it should have resulted in significantly increased suicide rates in the subsequent 10 years, which was not the case in the Montreal police nor in police elsewhere in Quebec. It is unfortunate that we did not have access to the age and sex distributions over this period for all the other Quebec police that were used as a comparison group, and thus we only were able to compare crude suicide rates. If police elsewhere had increased their proportion of women significantly more than in Montreal during this period, or if the average age of police did not increase or decreased elsewhere in Quebec, this could be a confounding factor that would possibly explain the differences observed. Although verbal reports indicate that this is not the case, without hard data it is impossible to eliminate this possibility. Nevertheless, given that the aging of police personnel would be considered to increase suicide risk, the sustained decrease in Montreal police suicides may still be considered to be impressive.

Following publication of the evaluation results in 2012, and the publicity generated by the initial program in 1997 and the following years, there was an increased awareness of the problem of suicide among police in the Province of Quebec and the potential for suicide prevention. Although none of the other police forces in Quebec established a comprehensive suicide prevention program like the program in Montreal, they all reported that they provided psychological support for police, and during this period, training programs for new police officers added more content concerning mental health and suicide prevention. Therefore, it is understandable that there was a significant decrease in suicides in the other police departments in the province during the most recent period, from 2009 to 2019, when compared with 1997-2008. However, their rate during this period was still significantly higher than the rate for Montreal police. Furthermore, the suicide rate outside Montreal during the entire 22 years after the Montreal program began, was not significantly lower than 
the rate during the prior 11 years before Montreal initiated its program.

\section{Conclusion}

We conclude that when a comprehensive suicide prevention program tailored to the work environment continues to be implemented, it may significantly decrease suicide rates, not only in the short term, but for extended periods of time. However, whenever a multifaceted program is implemented, unless more detailed evaluation research is conducted, it is not possible to identify which components of the program are more or less important in affecting reductions in suicide rates. One may reasonably assume that the publicity about the Montreal program in the rest of the province could have resulted in other police having increased psychological services available and greater awareness of the problem. The continued lower rate in Montreal suggests that having specific interventions, such as regular training of all police officers and their supervisors, and provision of a telephone helpline manned by volunteer police officers, contributed to the greater reduction in suicide rates in Montreal. However, more research is needed to validate these findings in different settings, and to better identify which aspects of comprehensive workplace suicide prevention programs are associated with reductions in deaths by suicide.

Most research on the effects of suicide prevention programs use proxy measures of suicide, such as selfreports on suicidal ideation or responses on scales assessing probable suicide risk. It is rare that programs are evaluated in terms of their impact on suicide death rates. This is understandable because of the low incidence of suicide fatalities, and the limited numbers of participants in prevention programs. Researchers who want to directly assess the impact of programs on deaths by suicide either need to have gigantic budgets to evaluate programs with very large numbers of participants, or they must wait many years, while still offering the program, in order to observe a sufficient number of fatalities to have hopes of obtaining significant findings. This provides a daunting challenge for researchers whose funding rarely extends beyond a few years, and who need to publish quickly to find and maintain jobs and to advance in their careers. Nevertheless, we believe it would be beneficial to the advancement of knowledge in suicidology to develop funding mechanisms for long-term longitudinal studies, and to find means of encouraging researchers to engage in long-term assessments of the impacts of prevention programs.

\section{References}

Charbonneau, L. (2000). Le suicide chez les policiers au Quebec: Enjeux methodologiques et etat de la situation [Suicide in Quebec police: Methodological issues and the current situation]. Population, 55(2), 367-378. https://doi.org/10.2307/1535038

Fields, G., \& Jones, C. (1999, June 1). Code of silence doesn't exist. USA Today, pp. A1-A2.

Finney, C., Stergiopoulos, E., Hensel, J., Bonato, S., \& Dewa, C. S. (2013). Organizational stressors associated with job stress and burnout in correctional officers: A systematic review. BMC Public Health, 13, 82. https://doi.org/10.1186/1471-2458-13-82

Hackett, D. P., \& Violanti, J. M. (Eds.). (2003). Police suicide: Tactics for prevention. Charles C. Thomas.

Loo, R. (2003). A meta-analysis of police suicide rates: Findings and issues. Suicide and Life-Threatening Behavior, 33(3), 313-325. https://doi.org/10.1521/suli.33.3.313.23209

Marzuk, P. M., Nock, M. K., Leon, A. C., Portera, L., \& Tardiff, K. (2002). Suicide among New York City police officers, 1977-1996. The American Journal of Psychiatry, 159(12), 2069-2071. https:// doi.org/10.1176/appi.ajp.159.12.2069

Milner, A., Spittal, M. J., Pirkis, J., \& LaMontagne, A. D. (2013). Suicide by occupation: Systematic review and meta-analysis. The British Journal of Psychiatry: The Journal of Mental Science, 203(6), 409-416. https://doi.org/10.1192/bjp.bp.113.128405

Milner, A., Witt, K., Maheen, H., \& LaMontagne, A. D. (2017). Suicide among emergency and protective service workers: A retrospective mortality study in Australia, 2001 to 2012. Work: Journal of Prevention, Assessment \& Rehabilitation, 57(2), 281-287. https://doi.org/10.3233/WOR-172554

Mishara, B. L., \& Martin, N. (2012). Effects of a comprehensive police suicide prevention program. Crisis, 33(3), 162-168. https://doi.org/10.1027/0227-5910/a000125

Sahai, H., \& Khurshid, A. (1996). Statistics in epidemiology: Methods, techniques and applications. CRC Publications.

Skegg, K., Firth, H., Gray, A., \& Cox, B. (2010). Suicide by occupation: Does access to means increase the risk? The Australian and New Zealand Journal of Psychiatry, 44(5), 429-434. https://doi.org/ 10.3109/00048670903487191

Webster, J. H. (2013). Police officer perceptions of occupational stress: The state of the art. Policing: An International Journal of Police Strategies \& Management, 36(3), 636-652. https://doi. org/10.1108/PIJPSM-03-2013-0021

Witt, K., Milner, A., Allisey, A., Davenport, L., \& LaMontagne, A. D. (2017). Effectiveness of suicide prevention programs for emergency and protective services employees: A systematic review and meta-analysis. American Journal of Industrial Medicine, 60(4), 394-407. https://doi.org/10.1002/ajim.22676

\section{History}

Received February 18, 2020

Revision received October 5, 2020

Accepted October 26, 2020

Published online May 4, 2021

\section{ORCID}

Brian L. Mishara

(D) https://orcid.org/0000-0003-2449-6269

\section{Brian L. Mishara}

CRISE-UQAM

C. P. 8888 Succ. Centre-ville

Montreal, QC H3C3P8

Canada

mishara.brian@uqam.ca 
Brian L. Mishara, PhD, is director of the Centre for Research and Intervention on Suicide, Ethical Issues and End-of-Life Practices (CRISE) and professor of psychology at the Université du Québec à Montréal, Canada. His extensive research focuses on identifying, evaluating, and disseminating best practices and ethical standards in suicide prevention. He consults and conducts suicide prevention training internationally.
Louis-Francis Fortin, M.Ps., has been a clinical psychologist for 18 years. He has been working for the Montreal police department (SPVM) since 2006, in counseling, psychotherapy, crisis intervention, safeguarding the high-risk unit, and implementing prevention programs, including the suicide prevention program Together for Life that decreased the police suicide rate by $79 \%$. 